\title{
Nuevos datos para la biografía de Ruy López de Villalobos, capitán general de la expedición hacia las islas Filipinas de 1542/
}

\section{New Information for Biography of Ruy López de Villalobos, Commander of Expedition to Philippines Islands of 1542}

\author{
David Cuevas Góngora \\ orcid.org/0000-0002-0550-4940 \\ Universidad de Málaga
}

El objetivo de este artículo es presentar los nuevos datos que aportamos para la reconstrucción biográfica de Ruy López de Villalobos, un malagueño, que dirigió una expedición por orden del virrey de México para establecer una colonia en las islas Filipinas en 1542 y hallar la ruta del tornaviaje a Nueva España.

Palabras Clave: Biografía; Ruy López de Villalobos; Familia; Filipinas.

The objective of this article is to show new data that we contribute for the biographic reconstruction of Ruy López de Villalobos, a native of Malaga, who led one expedition by order of the Viceroy of Mexico in order to establish a colony in the Philippines in 1542 and to find the route of tornaviaje to New Spain.

KEYwords: Biography; Ruy López de Villalobos; Family; Philippines.

Copyright: (C) 2016 CSIC. Este es un artículo de acceso abierto distribuido bajo los términos de una licencia de uso y distribución Creative Commons Attribution (CC-by) España 3.0. 


\section{Un malagueño poco conocido}

Diversos historiadores que se han ocupado de la armada de 1542 hacia las Islas de Poniente (actuales islas Filipinas) señalan la reducida información que se tiene en torno a la figura de Villalobos, comandante de la misma. Así, Eduardo Anguita Galán y José Moreno Gómez, en una obra que comprendía una serie de retratos biográficos sobre malagueños partícipes en la historia de América durante los siglos del XVI al XVIII, al abordar la persona de Ruy López de Villalobos advierten que no se dispone de fuentes directas sobre su biografía y que los escasos datos proceden de las referencias obtenidas de las «tres relaciones del viaje» conservadas. ${ }^{1}$ Misma conclusión a la que llega la historiadora Santos Arrebola. ${ }^{2}$ Por otro lado, en un estudio preliminar sobre la Relación de García de Escalante Alvarado, miembro de la expedición de Villalobos, el historiador Carlos Martínez Shaw mantiene la idea de la exigua información sobre nuestro personaje, aunque añade algunos esbozos más: su llegada a México en 1535, su nombramiento como alguacil mayor de la ciudad y sus nupcias con Juana de Ircio. Por último, el mismo Martínez Shaw le atribuye cierto parentesco con el virrey Mendoza, su designación como jefe de la expedición de 1542 y su fallecimiento en la isla de Amboina (islas Molucas) cuatro años después. ${ }^{3}$

\section{El linaje de los Villalobos de Málaga}

Durante una de las fases de la guerra de Granada contra el reino nazarí (1482-1492), los Reyes Católicos, Isabel y Fernando, conquistaron tras un prolongado asedio la ciudad de Málaga a los musulmanes en 1487. Inmediatamente se inició el proceso de repartimiento de solares, tierras y casas para los repobladores cristianos. Entre los nuevos habitantes figuró Juan de Villalobos, quien obtendría su vecindad en 1489, además de la consiguiente distribución de bienes inmuebles. ${ }^{4}$ De esta manera y según los libros de repartimientos de la ciudad de Málaga, Villalobos recibió varias propiedades: unas casas en la calle de las Guardas (hoy calle Compañía), otro inmueble en calle de los Carpinteros, el cual había pertenecido en un

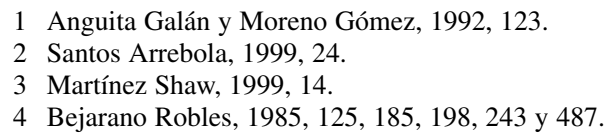


principio al mercader florentino Lorenzo de Rebeca, un solar ubicado a las afueras del recinto amurallado de Málaga, concretamente en el arrabal que daba a la denominada «Puerta de Granada» y por último dos molinos en la zona de Laolín (alquería musulmana), topónimo referido al actual municipio malagueño de Alhaurín de la Torre. Con anterioridad a su establecimiento en Málaga Juan había residido en la villa extremeña de San Martín de Trebejo o Trevejo, localidad donde había sido alcaide. ${ }^{5}$ Asimismo tuvo la posesión de la dehesa de «Azagala»; ${ }^{6}$ ubicada en la provincia extremeña de Badajoz y cercana a la Sierra de los Castaños. De su origen familiar tan solo se conoce lo mencionado por uno de sus hijos en una declaración realizada en la ciudad de México: «hijo de Villalobos, natural que fue de la Casa de Villalobos de León». ${ }^{7}$

Por otro lado, en el mismo año de 1489 Juan de Villalobos fue designado como mayordomo del concejo de la ciudad de Málaga, ${ }^{8}$ puesto que ejerció hasta $1491 .{ }^{9}$ A partir de aquí, el que sería padre de Ruy López de Villalobos inició su ascenso socio-político dentro de la oligarquía malacitana al desempeñar diversos cargos administrativos. De esta forma ocupó durante un año (1494-1495) el cargo de regidor de Málaga, ${ }^{10}$ para alcanzarlo de manera vitalicia en 1508 por merced real. ${ }^{11}$ En 1507 fue nombrado receptor de los bienes de los moriscos del Reino de Granada que se iban «allende», es decir, al norte de África. ${ }^{12}$ Dos años después (1509) y tras la toma por la armada de Pedro Navarro del enclave norteafricano del Peñón de Vélez de la Gomera a los musulmanes en 1508 se le concedió la alcaidía de esta fortaleza, elección debida quizás a su experiencia en este tipo de cargo cuando tiempo atrás había sido alcaide de Trevejo. En la recta final de su vida, y hallándose probablemente enfermo, renunció en 1511 a su regiduría en el concejo malagueño a favor de su hijo mayor Francisco. ${ }^{13}$ Un año después, en febrero de 1512, y mediante una carta, decía encontrarse

5 Documento en el que aparece Juan de Villalobos como alcaide de Trevejo, 30 de mayo de 1486, Archivo General de Simancas (AGS), Registro General del Sello, 148605, 212.

6 Documento fechado el 12 de marzo de 1494, AGS, Registro General del Sello, 149412, 173.

7 Relación de conquistadores de Nueva España, Declaración de Antonio de Luna, Archivo General de Indias (AGI), México, 1064, L.1, 128v.

8 Bejarano Robles, 1985, 198.

9 Ruiz Povedano, 1989, 114.

10 Idem.

11 Archivo Municipal de Málaga (AMM), Libro de Provisiones, V, 28r-29r.

12 AGS, Contaduría Mayor de Cuentas, 1. época, 267.

13 AMM, Libro de Provisiones, VI, 25v-26v. 
indispuesto para desempeñar sus ocupaciones,${ }^{14}$ meses después ya había fallecido. ${ }^{15}$

Juan de Villalobos estuvo casado en dos ocasiones. La primera de ellas lo había hecho con doña Constanza de Rivadeneira, tal vez con anterioridad a su establecimiento en Málaga, con la que tenía dos hijos: Francisco y Diego de Villalobos; trasladándose seguramente con ellos a Málaga en 1489, pues el nombre de Constanza aparece junto al de Juan en los repartimientos malagueños. ${ }^{16}$ De los hijos habidos en este primer matrimonio, Diego de Villalobos aparece en algunas escrituras protocolarias de Málaga junto a su hermano Francisco y con el título de licenciado. ${ }^{17}$ Por su parte, Francisco de Villalobos sucedió a su padre en los cargos de regidor de Málaga ${ }^{18}$ y alcaide del Peñón de Vélez de la Gomera, aunque este último puesto se lo cedió a su tío, llamado también Francisco de Villalobos. Francisco contrajo matrimonio con doña María de Góngora (enlace del que al parecer no hubo descendencia) y fallecería en 1521, siendo su mujer la heredera de sus bienes. ${ }^{19}$

Tras el fallecimiento de su primera mujer, doña Constanza, hecho que debió ocurrir entre finales del siglo XV y principios del XVI, Juan de Villalobos contrajo segundas nupcias con la madrileña Juana de Vargas, ${ }^{20}$ sobre cuya biografía hay escasos datos. Por una carta fechada en la ciudad de Málaga el 27 de marzo de 1518 sabemos que había otorgado su última voluntad ante el escribano Juan López de Portillo el 19 de noviembre de 1516. Sin embargo, y tras una consulta a las escrituras protocolares realizadas en ese año y pertenecientes a dicho escribano, esta resultó una búsqueda infructuosa al no hallarse tal documento pese a las referencias

14 Documento fechado en Málaga, 23 de febrero de 1512, Archivo Histórico Provincial de Málaga (AHPM), Protocolos Notariales de Málaga, 24.

15 Carta de doña Juana de Vargas, donde indica que su marido Juan de Villalobos ya era difunto, Málaga, 24 de noviembre de 1512, AHPM, Protocolos Notariales de Málaga, 24.

16 Bejarano Robles, 1985, 198.

17 Carta de venta del licenciado Diego de Villalobos y su hermano Francisco de Villalobos, regidor de Málaga, a favor de Pero Laso de la Vega, Málaga, 17 de junio de 1514, AHPM, Protocolos Notariales de Málaga, 75.

18 Francisco de Villalobos ocupó su regiduría hasta 1521, cuando renunció a ella por hallarse enfermo para desempeñar sus funciones. Documento fechado en Málaga, 6 de mayo de 1521, AHPM, Protocolos Notariales de Málaga, 76, 563r.

19 El nombre de su esposa se extrae de unos inventarios de bienes de Francisco de Villalobos, fallecido en 1521, donde declaró haber sido mujer de este. Documentos fechados en Málaga, 6 y 29 de octubre de 1521, AHPM, Protocolos Notariales de Málaga, 76, 310r-311r y 480r-482r. L.1, 128v.

20 Declaración de Antonio de Luna, hijo de doña Juana de Vargas, AGI, México, 1064, 
aportadas, una ausencia que podría deberse a factores de deterioro o pérdida de parte del legajo que lo contendría. No obstante, la propia carta de 1518 menciona algunas de las cláusulas testamentarias rectificadas. La mayoría hace referencia a temas de liquidación de deudas con particulares, mandas de misas, limosnas, donaciones, etc., pero los datos más significativos son sin duda la mención del lugar de sepultura tanto del alcaide Juan de Villalobos como de Juana de Vargas, así como la existencia de hijos del matrimonio. ${ }^{21} \mathrm{El}$ lugar de enterramiento se localizaba en una capilla ubicada en el monasterio de San Francisco de Málaga, ${ }^{22}$ donde pedía a sus hijos la realización de un retablo dedicado a las advocaciones de San Francisco y San Andrés, invirtiendo la cantidad de unos 15.000 maravedíes. A ello se añadía también la fabricación de un ornamento en blanco para dicha capilla, gastándose en él hasta 7.000 maravedíes.

Pese a la mención de hijos fruto del matrimonio entre Juan de Villalobos y su segunda esposa, Juana de Vargas, en la carta de 1518 no se indica ni el número ni la identidad de estos. Sin embargo, estas incertidumbres hallaron respuesta a raíz del hallazgo de una escritura de 1524 realizada en Málaga y otorgada por Juana de Vargas, donde sí se esclarece nombre, apellidos y número de los mismos:

Sepan quantos esta carta de poder vieren como yo doña Juana de Vargas, muger del alcaide [... roto] de Villalobos, mi señor que aya gloria, vezina que soy en esta muy noble y leal çibdad de Málaga [... roto] y en nombre de Rodrigo e Antonio de Villalobos y Bernardino de Vargas, mis hijos y del dicho alcaide Juan de Villalobos, my señor y como su madre legítima.... ${ }^{23}$

Este testimonio nos revela por tanto el número de hijos y sus nombres: Rodrigo de Villalobos (Ruy López de Villalobos), Antonio de Villalobos (en América adoptó la identidad de Antonio de Luna) y por último el menor de los tres, Bernardino de Vargas. ${ }^{24}$

21 Carta de doña Juana de Vargas otorgada ante el escribano Juan López Portillo, Málaga, 27 de marzo de 1518, AHPM, Protocolos Notariales de Málaga, 720.

22 El monasterio de San Francisco de Málaga se ubicaba extramuros de la ciudad, cercano al río Guadalmedina. Hoy día no se conserva nada del complejo monástico, tras sufrir la desamortización del siglo XIX. En la actualidad una plaza denominada de San Francisco y el auditorio Sala María Cristina señalan el lugar que ocupó el edificio conventual.

23 Carta de poder de doña Juana de Vargas a favor de Tomás Fernández de Plasencia, Málaga, 15 de julio de 1524, AHPM, Protocolos Notariales de Málaga, 138.

24 Era bastante frecuente durante la edad moderna que los individuos variasen sus apellidos, tomando en ocasiones los pertenecientes a abuelos paternos o maternos; seleccionando aquellos que aportaban mayor lustre a sus personas. Por otro lado, el nombre de Ruy era una forma antigua de referirse a Rodrigo. 


\section{Alcaides del Peñón de Vélez de la Gomera (1508-1520)}

En julio de 1508 el conde de Oliveto, Pedro Navarro, tomó a los musulmanes norteafricanos la fortaleza y enclave costero del Peñón de Vélez de la Gomera, dejando allí una pequeña guarnición con un capitán. El presidio estuvo bajo el mandado de Navarro hasta la llegada, en abril de 1509, del nuevo alcaide del lugar, Juan de Villalobos, quien se ocuparía del abastecimiento del enclave, por cuyo oficio sería remunerado con un salario anual estimado en unos 80.000 maravedíes. ${ }^{25}$

Juan de Villalobos mantendría la titularidad de la alcaldía de Vélez de la Gomera hasta poco antes del año de su fallecimiento en 1512, renunciando probablemente el cargo en su hijo Francisco de Villalobos, sin embargo este último lo acabaría cediendo a su tío de igual nombre, Francisco de Villalobos, verdadero protagonista de la caída del enclave norteafricano a manos de los musulmanes de la zona. Sobre la pérdida del presidio hispano no existe un consenso unánime entre los autores que han tratado tal hecho histórico, difiriendo las fechas, los protagonistas y las versiones. Por ello se ha optado por la reconstrucción del mismo a través de la comparación de tres narraciones del siglo XVI que narran este suceso: Descripción general del África y de las cosas peregrinas que allí hay, de Juan León el Africano (Venecia, 1550); ${ }^{26}$ Comentarios de la fundación y conquistas y toma del Peñón, de Baltasar de Collazos (Valencia, 1566): ${ }^{27}$ y por último, Descripción general de África, sus guerras y vicisitudes desde la fundación del mahometismo hasta el año 1571, de Luis del Mármol Carvajal (Granada, 1573). ${ }^{28}$ De esta consulta hemos extraído un cuadro comparativo sobre los sucesos acaecidos en Vélez de la Gomera desde 1508 hasta su pérdida (cuadro 1).

Apoyándonos en la documentación, la versión de Baltasar de Collazos es la más completa y la más próxima a la verdad, equivocándose únicamente en la fecha, pues la pérdida del Peñón no fue en 1516 sino en 1520, como sí lo apunta acertadamente León el Africano en su obra.

Primeramente contamos con la referencia al fallecimiento del alcaide Juan de Villalobos en Málaga en 1512. ${ }^{29}$ Luego constatamos la existencia

25 Gutiérrez Cruz, 1997, 264.

26 León el Africano, 2004, 308-309.

27 Collazos, 1566.

28 Mármol Carvajal, 1953, vol. I.

29 Carta de doña Juana de Vargas, donde indica que su marido Juan de Villalobos ya está difunto, Málaga, 24 de noviembre de 1512, AHPM, Protocolos Notariales de Málaga, 24. 
NUEVOS DATOS PARA LA BIOGRAFÍA DE RUY LÓPEZ DE VILLALOBOS

\begin{tabular}{|c|c|c|}
\hline $\begin{array}{l}\text { León el Africano } \\
\qquad(1550)\end{array}$ & $\begin{array}{l}\text { Baltasar de Collazos } \\
\text { (1566) }\end{array}$ & $\begin{array}{l}\text { Luis del Mármol Carvajal } \\
\qquad(1573)\end{array}$ \\
\hline \multirow[t]{3}{*}{$\begin{array}{l}\text { Toma del Peñón por Pedro } \\
\text { Navarro y construcción de } \\
\text { una torre. }\end{array}$} & $\begin{array}{l}\text { En } 1508 \text { Pedro Navarro se } \\
\text { apodera del Peñón y erige } \\
\text { una torre. }\end{array}$ & $\begin{array}{l}\text { En } 1508 \text { Pedro Navarro se } \\
\text { apodera del Peñón y erige } \\
\text { una torre. }\end{array}$ \\
\hline & Juan de Villalobos alcaide. & Juan de Villalobos alcaide. \\
\hline & $\begin{array}{l}\text { Muere Juan de Villalobos y } \\
\text { le sucede un hijo suyo, y } \\
\text { este deja por teniente a su } \\
\text { tío Francisco de Villalobos }\end{array}$ & $\begin{array}{l}\text { Hasta la pérdida del Peñón, } \\
\text { siempre fue alcaide Juan de } \\
\text { Villalobos. }\end{array}$ \\
\hline $\begin{array}{l}\text { Traición de un soldado } \\
\text { español, quién mató al al- } \\
\text { caide por seducir a su } \\
\text { mujer. }\end{array}$ & $\begin{array}{l}\text { Traición de dos moros que } \\
\text { contrataban con el alcaide, } \\
\text { ofrecimiento de una esclava } \\
\text { negra que sabía de la alqui- } \\
\text { mia del oro, pero resulta ser } \\
\text { un negro disfrazado, y dan } \\
\text { muerte al alcaide y a su } \\
\text { mujer. }\end{array}$ & $\begin{array}{l}\text { Traición de dos moros } \\
\text { alquimistas de Fez que, en } \\
\text { asociación con un soldado } \\
\text { de la guarnición que estaba } \\
\text { molesto con el alcaide por } \\
\text { sospechas de andar con su } \\
\text { mujer, matan al alcaide y } \\
\text { se apoderan de la torre. }\end{array}$ \\
\hline \multirow[t]{3}{*}{$\begin{array}{l}\text { Toma de la fortaleza por los } \\
\text { musulmanes en } 1520 \text {. }\end{array}$} & Ocurrió en 1516. & $\begin{array}{l}\text { Sucedió el } 20 \text { de diciembre } \\
\text { de } 1522 .\end{array}$ \\
\hline & $\begin{array}{l}\text { Sabida la noticia desde } \\
\text { Gibraltar sale don Juan de } \\
\text { Velasco para recuperar la } \\
\text { plaza, también se envía un } \\
\text { socorro desde Málaga. }\end{array}$ & \\
\hline & $\begin{array}{l}\text { Ambos socorros no pueden } \\
\text { hacer nada y terminan re- } \\
\text { gresando. }\end{array}$ & \\
\hline
\end{tabular}

de un hermano del alcaide con el nombre de Francisco de Villalobos a raíz de una carta de obligación de doña Juana de Vargas de 1512, segunda esposa de Juan: «que Francisco Suñer, mercader, debe al dicho alcaide Juan de Villalobos, mi señor, de los dineros que Francisco de Villalobos, hermano del dicho alcaide...». ${ }^{30}$

30 Carta de obligación de doña Juana de Vargas, Málaga, 20 de agosto de 1512, AHPM, Protocolos Notariales de Málaga, 4. 
Así como su designación como capitán y alcaide del Peñón de Vélez de la Gomera en documentos malacitanos de 1514 y 1519: «Sepan quantos esta carta vieren como yo Francisco de Villalobos, alcaide e capitán del Peñón de sobre veles de la Gomera otorgo e conosco...». ${ }^{31}$

Por otro lado, algunos autores han unido en una misma persona al Francisco de Villalobos, hijo de Juan, con el hermano de este al llevar ambos el mismo antropónimo. ${ }^{32}$ Pero si hacemos un ejercicio de cotejo de sus firmas, se observa que se trata de dos personas distintas, estableciéndose por lo tanto la contemporaneidad de dos Francisco de Villalobos, tío y sobrino. De esta manera, y tomando dos puntos de comparación, se aprecian las siguientes diferencias caligráficas:

1.-Forma de escribir el nombre.

2.-Motivos gráficos donde encajan los nombres.

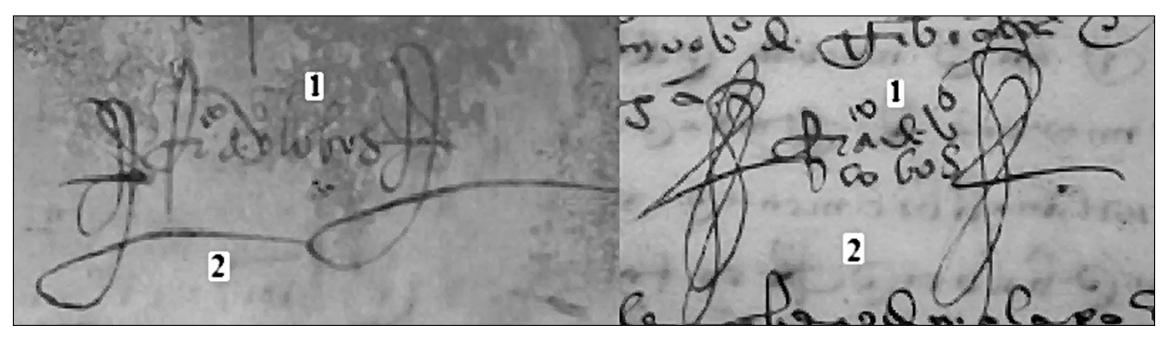

Izquierda: Firma de Francisco de Villalobos, hijo de Juan y regidor de Málaga. Derecha: Rúbrica de Francisco de Villalobos, alcaide del Peñón y hermano de Juan. Fuentes: AHPM, Protocolos Notariales de Málaga, 75, Málaga, 17 de junio y 6 de agosto de 1514, respectivamente.

En cuanto a la versión de la traición que dio lugar a la muerte del alcaide Francisco de Villalobos y la pérdida del presidio de Vélez de la Gomera, la narrada en la obra de Baltasar de Collazos en cierta manera está corroborada documentalmente por una carta que Pedro de Castañeda envía al duque de Medina Sidonia en torno a 1520:

Que el Peñón de Vélez lo tomaron los moros a los cristianos desta manera, que le truxeron tres o quatro moros a vender al alcayde una esclava y ya vendida le rogaron que los toviese allí tres o quatro días hasta que los que venían en pos dellos por el esclava que

31 Carta de venta de un esclavo negro del alcaide Francisco de Villalobos a favor de Juan Romero, vecino de Málaga, Málaga, 6 de agosto de 1514, AHPM, Protocolos Notariales de Málaga, 75. Carta de poder de Francisco de Villalobos a favor de Gastón de Caizedo, Málaga, 12 de julio de 1519, AHPM, Protocolos Notariales de Málaga, 76.

32 González Arévalo, 2006, 351. 
trayan hurtada perdiesen el trato y teniéndolos desta manera aguardaron a que estaba el alcayde solo en la torre y la gente abaxo e allí lo mataron e se alçaron con la torre. ${ }^{33}$

Por último, encontramos dentro de las actas capitulares del concejo malagueño, ubicadas en su Archivo Municipal, el envío desde el puerto de Málaga de un socorro de bastimentos y hombres al Peñón de Vélez de la Gomera tras conocerse su caída en manos musulmanas, ${ }^{34}$ tal y como recogía Collazos en sus Comentarios.

\section{Hermanos de padre y madre: Antonio de Villalobos y Bernardino de Vargas}

En apartados anteriores se ha hablado de Francisco y Diego de Villalobos, hermanastros de Ruy López de Villalobos. Es, por tanto, el momento de centrarnos ahora en sus hermanos Antonio y Bernardino.

Antonio de Luna o de Villalobos reconocía en México por declaración propia, su filiación como hijo de Villalobos (sin indicar el nombre) y doña Juana de Vargas. Este hermano de Ruy López de Villalobos había participado, según él, en la conquista de las regiones de Santa Marta y Cartagena. ${ }^{35}$ No obstante, no hay una indicación clara en la documentación, ya que la única referencia posible y con ciertas reservas sería relacionarlo con un tal Villalobos, personaje que figuró como capitán de infantería en la hueste comandada por el gobernador de Santa Marta, García de Lerma, en $1528{ }^{36}$ Posteriormente, Antonio dirigió sus pasos hacia Nueva España, viaje que ocurrió entre 1534 o 1535, afincándose en la ciudad de México, donde finalmente contraería matrimonio con la criolla Isabel de Caicedo, hija de Antón de Caicedo y doña María Montes de Oca. El suegro de Antonio era un antiguo conquistador llegado en la expedición de Pánfilo de Narváez de 1520 y por cuyos servicios en la conquista de México fue recompensado con las encomiendas de Teguaçin, Teguadín, Periván, Cuecoromaçón y Testitlitán. Sin embargo, explicaba Antonio de Luna que al tiempo del fallecimiento de Caicedo su hija no heredó las encomiendas, pues aun no

33 Carta enviada por Pedro de Castañeda al duque de Medina Sidonia, 1520-1521, Archivo Histórico Nacional (AHN), Osuna, C. 1635, D. 216.

34 Documento fechado en Málaga, 15 de octubre de 1520, AMM, Libro IV Actas de Cabildo, 24-26 y $40-43$.

35 Declaración de Antonio de Luna, AGI, México, 1064, L.1, 128.

36 Relación de la gente que va en compañía de García de Lerma, gobernador de la provincia de Santa Marta, AGI, Contratación, 5536, L.2, 119. 
había llegado a Nueva España la merced real que instituía la posibilidad de la sucesión de las hijas en las encomiendas de sus padres. Esta tardanza de la normativa le llevaba por tanto a una situación de precariedad, no quedándole otra cosa más que la súplica a las autoridades coloniales de algún tipo de remuneración para su manutención. ${ }^{37}$ Asimismo, el retraso de la aplicación de la nueva ley de sucesión en torno a las encomiendas condicionó a que doña María Montes de Oca, viuda de Caicedo, fuese la benefactora de las suyas. Motivo que llevó a don Antonio de Luna a suscitar varios pleitos con la viuda, quien además era su suegra, con la firme intención de recibir las encomiendas correspondientes por el matrimonio con su hija Isabel. ${ }^{38}$ Tras numerosos juicios, don Antonio conseguiría finalmente retener para sí las encomiendas de Tarecuato y Perivan.

La descendencia habida de su matrimonio con Isabel de Caicedo fue de al menos dos hijos: Rodrigo de Luna, quien sucedería a don Antonio en la encomienda de Tarecuato, ${ }^{39}$ y doña Mariana de Luna, que casaría en dos ocasiones, la primera de ellas con el cronista y descendiente de conquistadores Baltasar de Obregón.

Don Antonio de Luna amplió sus miras económicas y enriquecimientos, apostando por la extracción de perlas en la zona de California. Así, en torno a la segunda mitad del siglo XVI (1563) preparó una expedición hacia la riqueza perlífera californiana. Mención del viaje hizo el cronista Baltasar de Obregón en su crónica escrita en México hacia 1584 y conservada en el Archivo General de Indias (ya que se halló en él), pues ningún otro documento lo refiere:

fui el primer descubridor de minas en esta provincia [Chiametla] quando vine del viaje que ise a la ysla Cardena de la Carnifería [sic Califonia] en compañía de don Antonio de Luna mi suegro, antes que se poblase, viniendo juntos [...] de algunas cossas delas que hago rrelaçión a vuestra magestad soy testigo de vista espeçialmente delas costas desde Acapulco hasta el rrío del Tizón California ala qual fui a servir a vuestra magestad en compañía de don Antonio de Luna mi suegro que fue a sacar perlas en la dicha ysla en la qual sacó en tres días mucha cantidad de ostras con los buzos naturales de la isla [...] y si ffuera el dicho don Antonio a tiempo y sazón y perseverara en el viaje no se duda sino que sacara cantidad de perlas gruesas. ${ }^{40}$

37 Declaración de Antonio de Luna, AGI, México, 1064, L.1, 128.

38 Pleito entre Antonio de Luna y María Montes de Oca, 1558, AGI, Justicia, 158, N.1.

39 El cronista mestizo Baltasar Dorantes de Carranza recogió en su obra que Rodrigo de Luna era encomendero y nieto de Antón de Caicedo, aunque colocó al margen que este «es loco». Dorantes de Carranza, 1987, 146.

40 «Historia de los descubrimientos antiguos y modernos de Nueva España y Nuevo México», México, 1584. AGI, Patronato, 22, R.7, 86r-86v. y 181v. 
Tiempo después, don Antonio casaría a su hija Mariana de Luna con Baltasar de Obregón, hecho ya reseñado en la propia obra de Obregón y confirmado por la documentación concerniente a una información realizada por este en la ciudad de México hacia 1584. Entre los testigos presentados figuró el caballero de la Orden de Santiago don Luis de Castilla, quien enumeró los antecedentes familiares de ambos cónyuges:

dixo que conoce a los dichos Baltasar de Obregón y conoce a la dicha doña Mariana de Luna su muger, hija ligítima de don Antonio de Luna y conoçió a Baltasar de Obregón su padre y a la dicha doña Beatriz de Çayas su madre y conoció al dicho Rodrigo de Vaeça y a la dicha Mari López de Obregón sus abuelos, y conoció assimismo al dicho Antón de Caicedo aguelo de la dicha doña Mariana de Luna y conoció assimismo a la dicha doña María Montes de Oca muger que fue del dicho Antón de Caicedo aguela de la dicha doña Mariana de Luna. ${ }^{41}$

Este enlace Obregón-Luna no trajo consigo descendencia alguna, tal vez por la muerte prematura de Baltasar de Obregón, pues doña Mariana de Luna volvió a casar con don Cristóbal de Cárcamo, hijo del oidor don Bernabé de Cárcamo y su mujer doña Catalina de Gálvez. De su segundo esposo, doña Mariana dio a luz un hijo, Francisco de Cárcamo y Luna. ${ }^{42}$

La última aparición de don Antonio de Luna en la documentación procede de 1582, cuando participó como testigo en la probanza realizada por su sobrino Ruy López de Villalobos «el mozo» ${ }^{43}$, expresando su parentesco: «e queste testigo es tío del dicho Ruy López de Villalobos, hermano de su padre». ${ }^{44}$ En cuanto a la fecha de su fallecimiento, esta debió de ocurrir a finales del siglo XVI, pues hacia 1600 su hijo Rodrigo de Luna ya era el titular de las encomiendas paternas.

El menor de los hermanos de Ruy López de Villalobos, Bernardino de Vargas, viajó con este a México en 1535; acompañándole posteriormente en su expedición a las Islas de Poniente en $1542,{ }^{45}$ donde hallaría la muerte en la isla de Sarragán un año después. ${ }^{46}$ Por otro lado, cabría la hipótesis

41 Información de Baltasar de Obregón, México, 8 de marzo de 1584, Declaración de don Luis de Castilla, AGI, México, 217, N.25, 2v-4r.

42 Fernández de Recas, 1961, 75.

43 Este Ruy era hijo del malagueño Ruy López de Villalobos y de su mujer, doña Juana de Ircio.

44 Información de méritos y servicios de Pedro de Ircio y Ruy López de Villalobos, Declaración de Antonio de Luna, México, 15 de enero de 1582, AGI, Patronato, 77, N.1, R.2, 34r-35v.

45 Ibidem, Declaración de Juan del Hierro (7v-8v), Juan Carlos de Bonilla (9r.-10v.) y Rodrigo de Barrionuevo (11v.-12v.).

46 Colección de Documentos Inéditos para la Historia de España, Madrid, 1882 (reimprime Kraus Reprint, Alemania, 1966), vol. 78, 500. 
de su posible participación en la armada dirigida al Río de la Plata de don Pedro de Mendoza, pues aparece entre la documentación un Bernardino de Vargas solicitando licencia para llevar un caballo. ${ }^{47}$ Tal referencia podría pasar por anecdótica o simple caso de homonimia, si no fuese porque en la misma armada figuró a su vez un Rodrigo de Villalobos, que había sido nombrado tesorero ${ }^{48}$ de la región rioplatense, aunque dejó este cargo antes de partir la expedición mendocina en $1535 .{ }^{49}$ Pero a falta de información más precisa sobre la naturalidad y progenitores de estos, resulta casi imposible establecer con certeza que ambos sean los malacitanos Rodrigo de Villalobos y su hermano menor Bernardino de Vargas.

\section{Ruy López de Villalobos: De México a las Islas del Poniente (1535-1546)}

Tras este recorrido en torno a los antecedentes familiares de Ruy López de Villalobos es momento de centrarnos en su biografía particular. Desvelada queda ya la identidad de sus padres ${ }^{50} \mathrm{y}$ hermanos según hemos explicado en páginas anteriores. En cuanto a su fecha de nacimiento estamos en situación de poder establecerla en un marco temporal definido que quedaría comprendido entre los años de 1506 a 1509, extraído de la propia declaración de Villalobos en una carta de venta concerniente a unas propiedades ubicadas en Málaga: «porque soy menor de veinte e cinco años e mayor de veinte». ${ }^{51}$

47 Real Cédula, Palencia, 28 de septiembre de 1534, AGI, Buenos Aires, 1, L.1, 40v.

48 Real Provisión nombrando a Rodrigo de Villalobos como tesorero del Río de la Plata, Toledo, 21 de mayo de 1534, AGI, Buenos Aires, 1, L.1, 23v-25r. Dos años antes (1532) se le había entregado una Real Cédula donde se le nombraba como tesorero a la espera de expedirle la Real Provisión (Real Cédula, Segovia, 5 de septiembre de 1532, AGI, Indiferente, 422, L.15, 174v). Asimismo se le concedía un regimiento en el Río de la Plata en la ciudad donde residiese el gobernador de la región: Concesión de regimiento, Palencia, 6 de agosto de 1534, AGI, Buenos Aires, 1, L.1, 19r; Licencia para llevar caballos, Ibidem, 19v; Licencia para llevar esclavos, Ibidem, 21r; Licencia para comerciar, Madrid, 11 de diciembre de 1534, Ibidem, 54r-54v.

49 Real Provisión concediéndole el cargo de tesorero del Río de la Plata a Gonzalo de Alvarado por renuncia de Rodrigo de Villalobos, Madrid, 20 de agosto de 1535, AGI, Buenos Aires, 1, L.1, 23v.

50 El mismo Villalobos menciona a sus progenitores en una carta de venta realizada en Málaga en 1530: «yo, Rodrigo de Villalobos, hijo del alcaide Juan de Villalobos, alcaide de Trebejo, ya difunto y de doña Juana de Vargas, su mujer, estante al presente en esta muy noble y muy leal çibdad de Málaga». Carta de venta de Rodrigo de Villalobos, Málaga, 31 de agosto de 1530, AHPM, Protocolos Notariales de Málaga, 146.

51 Idem. 
Nada más sabemos de su estancia en Málaga, puesto que en 1535 ya se encontraba en México y con el nombre cambiado de Rodrigo de Villalobos a Ruy López de Villalobos. Aunque como ya apuntamos en el caso de su hermano menor, Bernardino de Vargas, tal vez intentase con anterioridad su marcha hacia las Indias en la armada de don Pedro de Mendoza con destino al Río de la Plata como tesorero, cargo que dejaría antes de partir la expedición. Si esto fuese así y ambos fueran la misma persona, cabría la hipótesis de que tras esta renunciación estuviese el nombramiento como virrey de Nueva España en 1535 de don Antonio de Mendoza, al que se le atribuye cierto parentesco con Ruy López de Villalobos, prefiriendo tal vez este último la protección de tan alto funcionario.

Esta mención de ser pariente del virrey Mendoza no está justificada en profundidad. ${ }^{52}$ Por nuestra parte y tras indagar en la correspondencia del II conde de Tendilla, don Iñigo López de Mendoza, padre del virrey, localizamos una carta que este envía al alcaide Juan de Villalobos (padre de Ruy) dirigiéndose a él en los siguientes términos: «pariente, señor y amigo». ${ }^{53}$ Sin embargo, dudamos si tal tratamiento es un simple protocolo de cortesía o ciertamente había alguna relación de parentesco entre ellos. La otra posibilidad estaría en torno a la madre de Ruy, doña Juana de Vargas, emparentada con el tesorero Francisco de $\operatorname{Vargas}^{54}$ y perteneciente al linaje madrileño del mismo apellido, puesto que una hija de este, doña Catalina de Vargas, estaba casada con el virrey don Antonio de Mendoza.

Por una información levantada por uno de sus hijos ${ }^{55}$ sabemos que Ruy López de Villalobos viajó a Nueva España en 1535 entre la comitiva del virrey, pues varios testigos de la probanza le vieron llegar con él. ${ }^{56}$ Una vez instalado en México, el malagueño Villalobos casó con doña Juana de

52 El cronista Bernal Díaz del Castillo recoge esta relación entre el virrey y Ruy López de Villalobos con motivo del apresto de la armada hacia las Islas de Poniente: «Mendoza mandó que tomasen ciertos navíos, los mejores y más buenos de los trece que enviaba el adelantado a descubrir la China por la banda del poniente, y envió por capitán de los navíos a un su deudo que se decía fulano de Villalobos». Díaz del Castillo, 1984, v. 2, 415.

53 Osorio Pérez, Szmolka Clares y Moreno Trujillo, 1996, v. II, 734.

54 Cruces Blanco, 1987, 212.

55 Ruy López de Villalobos el «mozo» hijo del malagueño Ruy López de Villalobos presentó una información de méritos y servicios correspondiente a los de su abuelo materno Pedro de Ircio y de su padre Ruy López de Villalobos. Se trata de varias probanzas realizadas entre 1573 y 1582 . AGI, Patronato, 77, N.1, R.2.

56 Declaración de Pedro de Saucedo (8v-9r), Juan Carlos de Bonilla (9r-10v), Diego Agúndez (10v-11v), Rodrigo de Barrionuevo (11v-12v., este incluso vino con Ruy López desde España) y Francisco de Valdenebro (12v-13v), Ibidem. 
Ircio, hija única de Pedro de $\operatorname{Ircio}^{57}$ y de su esposa doña María de Andrada, hija esta última del conquistador Leonel de Cervantes (llegó con Pánfilo de Narváez) y de Leonor de Andrada.$^{58}$ El suegro de Villalobos era un antiguo conquistador partícipe en la campaña realizada por el extremeño Hernán Cortés para la conquista del imperio mexica (1519-1521). Fue recompensado a tenor de sus servicios con la encomienda de Maxçalcingo, cuya titularidad poseyó hasta su fallecimiento en 1526, ya que solo tenía por heredera a su única hija, que en base a la normativa del momento en cuanto a la ley de sucesiones en las encomiendas, quedaba excluida. Así que la encomienda de Pedro de Ircio fue objeto de distribución entre la Corona y diversos conquistadores. ${ }^{59}$ Cuatro años después de su muerte, Martín de Ircio, su hermano, realizó una probanza póstuma que contenía los méritos y servicios del ya desaparecido Pedro de Ircio. ${ }^{60}$

En cuanto a la averiguación de si hubo descendencia entre el malagueño Ruy López de Villalobos y doña Juana de Ircio, la primera referencia con la que contamos es la de fray Jerónimo de Santisteban acompañante de Villalobos en su expedición hacia las Islas de Poniente en 1542. Se trata de una carta que el fraile envió al virrey de Nueva España desde Conchín el 22 de enero de 1547, relatando los acontecimientos de la armada, donde cuenta: «acuérdese vuestra señoría que prometió a Ruy López según el me dijo que sería padre de sus hijos». ${ }^{61}$ Luego tenemos la información levantada por Ruy López de Villalobos «el mozo», reconociendo ser hijo de Ruy López de Villalobos y doña Juana de Ircio. ${ }^{62}$ Asimismo algunos de los testigos que depusieron en la probanza afirmaron lo siguiente: Juan del Hierro dijo que vio venir desde Acapulco a México a doña Juana de Ircio embarazada, ${ }^{63}$ y el testigo Diego de Agúndez declaró que «parió del dicho Ruy López de Villalobos su marido legítimo çiertas criaturas». ${ }^{64}$

Por otro lado, antes de su nombramiento como capitán general y teniente de gobernador de las Islas de Poniente (futuras islas Filipinas),

57 Thomas, 2001, 98.

58 Ibidem, 201-202.

59 Información de los méritos y servicios de Pedro de Ircio y Ruy López de Villalobos, Declaración de Juan de Vera, AGI, Patronato, 77, N.1, R.2, 31r-32v.

60 Información de los méritos y servicios de Pedro de Ircio y Ruy López de Villalobos, AGI, Patronato, 77, N.1, R.2. 14r-14v.

61 Carta de Jerónimo de Santisteban al virrey de Nueva España, Conchín de la India del Rey de Portugal, 22 de enero de 1547, AGI, Patronato, 20, N.5, R.12, 5v.

62 AGI, Patronato, 77, N.1, R.2.

63 Declaración de Juan del Hierro, 7v-8v, Ibidem.

64 Declaración de Diego Agúndez, 10v-11v, Ibidem. 
Ruy López desempeñó algunos cargos político-administrativos en Nueva España. Según los testigos interrogados nuestro malagueño desempeñó los cargos de alguacil mayor de México ${ }^{65}$ y visitador de la provincia de Acapulco ${ }^{66}$ En cuestiones militares parece ser que Villalobos intervino en la denominada guerra del Mixtón (1540-1542), conflicto que tuvo como escenario la región noroccidental del virreinato de Nueva España, conocida como Nueva Galicia, pues Villalobos figuró como jinete a las órdenes del capitán Iñigo López de Anunçibay ${ }^{67}$ Según cuenta el cronista Baltasar de Obregón en su obra:

cantada la primera victoria de xpianos contra esta rrebelión matando, rindiendo y desbaratando a los indios contrarios [...] y por ser victoria tan famosa y digna de loa y memoria, quise que no se quedase sepultada ni olvidados los nombres de tan esforçados cavalleros, los quales fueron el capitán Iñigo López de Unçibay, Antonio Sotelo de Betanços, Joan de Alvarado, Galván Escobar, Bartolomé Rodríguez de Fuenlabrada, Joan Locaño Rrabamartín, Miguel de Ybarra capitán de çinquenta hombres, Agustín Guerrero, Joan de Saldivar, Rui López de Villalobos e Joan de Mendoça. ${ }^{68}$

Finalizado el conflicto con la derrota de la coalición de las tribus chichimecas por las armas españolas, el virrey don Antonio de Mendoza reanudó los preparativos de la armada con destino a las Islas de Poniente del Mar del Sur, cumpliendo la capitulación que había concertado con su ya desaparecido socio don Pedro de Alvarado. ${ }^{69}$

El virrey Mendoza eligió para la dirección de la armada al malagueño Ruy López de Villalobos, nombrándolo teniente de gobernador y capitán general de los territorios colonizados, además de insistirle en el hallazgo del tornaviaje, es decir, la ruta de regreso desde las Islas de Poniente a México. Sin embargo, no es nuestra intención contar los detalles de la expedición,

65 Declaraciones de Pedro de Saucedo (8v-9r), Juan Carlos de Bonilla (9r-10v), Diego Agúndez, este último dijo que ocupó el puesto de alguacil mayor por muerte del anterior, Diego Hernández de Proaño, (10v-11v) y Francisco de Valdenebro (12v-13v), Ibidem.

66 Así lo afirmaron Juan Carlos de Bonilla (añadiendo también que había sido alcalde mayor) y Diego Agúndez, Ibidem.

67 De origen malagueño, para saber más datos véase Cuevas Góngora, 2010.

68 AGI, Patronato, 22, R.7, 26r.

69 Don Pedro de Alvarado, antiguo conquistador de México a las órdenes de Hernán Cortés y conquistador de Guatemala, había capitulado en 1538 con la corona española levantar una armada para explorar, conquistar y poblar las tierras que se ubicaban en el Océano Pacífico. En 1540 arribó a las costas pacíficas de Nueva España, donde se entrevistó con el virrey Mendoza, quien se interesó por su proyecto llegando a un acuerdo entre ambos para asociarse en la empresa. Sin embargo el estallido de la rebelión chichimeca retrasó los preparativos, Alvarado por petición del propio virrey intervino en el conflicto pero con tan mala fortuna que en uno de los ataques se le cayó un caballo encima; dejándolo muy malherido, muriendo a los pocos días. 
pues existe una abundante bibliografía que se ha ocupado de ella en diversos aspectos diplomáticos, evangélicos, históricos y geográficos, ${ }^{70}$ además, nuestro principal objetivo es profundizar en la persona de Villalobos, más desconocido para la historiografía. No obstante, nos interesa el dato relativo a la propiedad de uno de los navíos que componían la armada, pues era del propio Villalobos, en cuya construcción había gastado la casi totalidad de su hacienda y la de su mujer. Varios testigos certificaron la construcción del navío, don Antonio de Luna, Juan de Castilla, Juan de Padilla, fray Sebastián de Trasierra y fray Lorenzo de Herrera, estos tres últimos acompañaron a Villalobos en su expedición. ${ }^{71}$ El navío era el llamado «San Juan», como señala fray Sebastián de Trasierra. Embarcación con la que se hicieron los dos intentos de búsqueda del tornaviaje desde las Filipinas hacia Nueva España, ambos infructuosos ante el regreso de la nave al punto de partida. El primero corrió a cargo del capitán Bernardo de la Torre (1543) y el segundo lo dirigió el vizcaíno Iñigo Ortiz de Retes (1545).

Ruy López de Villalobos terminaría enfermando en la isla de Ambón o Amboina (cerca de las Molucas), donde fallecería en 1546 siendo enterrado en un poblado. Sobre la muerte de Villalobos el fraile y testigo fray Sebastián de Trasierra dice:

\begin{abstract}
Fueron a inbernar a una ysla nombrada Ambón, donde estando en ella vio este testigo como el dicho capitán cayó malo y a lo que este testigo entendió fue la enfermedad de la pena que reçibió de no aver podido efetuar lo que su magestad deseava que era ganar aquellas islas y hazer aquel descubrimiento e luego murió e antes que muriese este testigo le comulgó y estava tan pobre como lo vieron después que vieron su testamento porque rrogava y encargava a este testigo y a los demás rreligioso que avían ydo con él que por amor de dios le dixesen algunas misas no embargante que no dexava con que pagar la limosna dellas. ${ }^{72}$
\end{abstract}

De los hijos del malagueño Villalobos solo nos queda memoria de uno de ellos, Ruy López de Villalobos «el mozo», protagonista de la probanza sobre los méritos y servicios de su padre y su abuelo materno (Pedro de Ircio). El fin de esta información no era otro que la obtención de alguna remuneración ya fuese en encomiendas, rentas o cargos públicos por parte

70 Véase Ortuño Sánchez-Pedreño, 2005. Anguita Galán y Moreno Gómez, 1992. Santos Arrebola, 1999. Varela, 1983. Gil, 1989. Alonso, 1989. Landín Carrasco, 1984, 75-77.

71 Sus declaraciones se hallan en AGI, Patronato, 77, N.1, R.2: Declaración de Antonio de Luna (34r-35r), Juan de Padilla (32r-34r), Juan de Castilla (37r-38v), fray Sebastián de Trasierra $(43 v-46 r)$ y fray Lorenzo de Herrera $(46 r-47 v)$.

72 Declaración de fray Sebastián de Trasierra en la probanza de Ruy López de Villalobos «el mozo», Mechuacán, 22 de febrero de 1582, AGI, Patronato, 77, N.1, R.2, 43v-46v. 
NUEVOS DATOS PARA LA BIOGRAFÍA DE RUY LÓPEZ DE VILLALOBOS

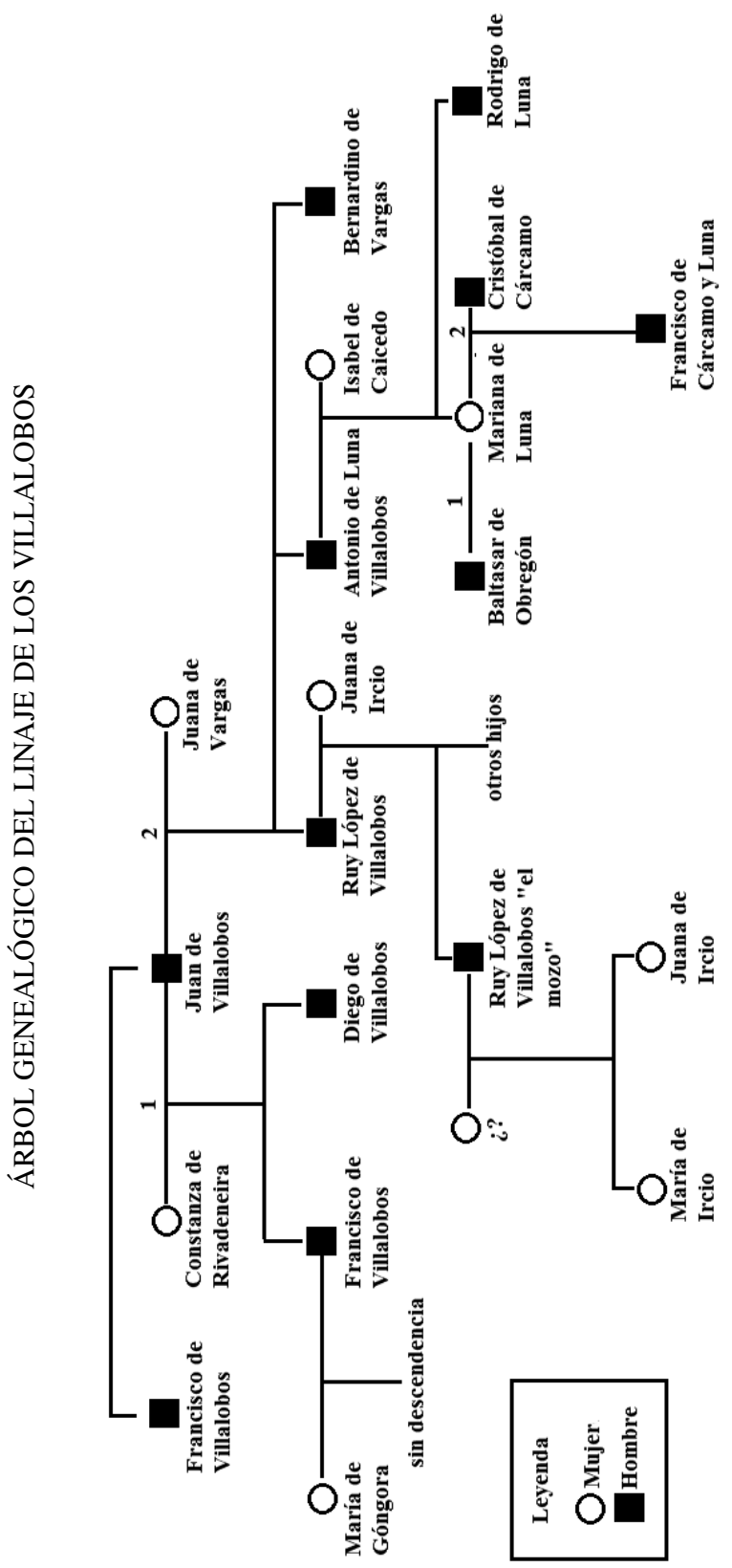


del solicitante. Así pues, pedía la suma de 2.000 pesos de renta, bien procedentes de la Caja Real, de encomiendas o el oficio de alguacil mayor, además de que dicha merced le fuese concedida también por la vida de una hija. Esta solicitud se demoró hasta 1599.73

Ruy López de Villalobos «el mozo» realizó varios viajes desde México a España. El primero de ellos fue en 1573 y había embarcado en la flota comandada por el capitán general Juan de Alcega en su ruta desde Nueva España a la Península. El asunto del viaje era: «entender en çiertos negoçios tocantes a mi hazienda», ${ }^{74}$ actividades que seguramente tendrían relación con la presentación en el Consejo de Indias de la probanza de méritos de su padre y abuelo con la esperanza de ser remunerado. Esta primera estancia en España se dilató por tiempo de cinco años, pues el 2 de mayo de 1578 el joven Ruy se hallaba en la ciudad de Sevilla a la espera de conseguir su licencia para volver a México, trámite que exigía la presencia del escribano de la Casa de la Contratación sevillana, que en su caso era Álvaro de Salinas, y la comparecencia de tres testigos que asegurasen que se trataba del mismo Ruy López que había venido de México a España. Estos fueron el artillero y sevillano Iñigo de Espinosa, compañero de viaje en la flota de Alcega; el labrador y vecino de la población mexicana de Atisco Antonio Roldán, quien describió a Villalobos así: «es un hombre de treynta e cinco años mediano de cuerpo, moreno, delgado y tiene una señal grande de herida en la cabeça a la parte derecha»; y por último el clérigo Diego de León, quien conocía al joven Villalobos desde hacía catorce años, cuando residió en México. ${ }^{75}$

El segundo viaje tuvo lugar en 1585, contando en esta ocasión con el permiso de don Pedro Moya de Contreras, arzobispo de México. ${ }^{76}$ Esta segunda estancia en España duró hasta 1589, aunque el rey le había otorgado tres años antes licencia para volver a México, concretamente el 26 de junio de $1586 .{ }^{77}$ Sin conocer las causas exactas, la partida de Ruy López de

73 Las cédulas y cartas relativas a la concesión de las mercedes solicitadas por Ruy López de Villalobos «el mozo» se encuentran al final de la información de méritos y servicios que presentó de su abuelo y padre y contenidas en AGI, Patronato, 77, N.1, R.2.

74 Petición de licencia de pasaje de Ruy López de Villalobos para volver a México, Sevilla, 2 de mayo de 1578, AGI, Indiferente, 2059, N.83.

75 Idem.

76 Carta del arzobispo don Pedro Moya de Contreras dando licencia a Ruy López de Villalobos para ir a España, México, 2 de abril de 1585, AGI, Indiferente, 2063, N. 58.

77 La carta del rey donde concede a Villalobos la licencia para volver a México (San Lorenzo, 26 de junio de 1586) se halla en AGI, Indiferente, 2064, N.137. 
Villalobos «el mozo» se demoró hasta 1589, de ahí que volviera a solicitar pasaje. Finalmente partiría a su destino junto con dos criados y la cédula que le otorgaba la merced de 2.000 pesos por los servicios de sus antepasados. ${ }^{78}$

Los últimos datos de la vida del hijo del malagueño se resumen a su casamiento y descendencia, aspectos que dilucidamos de la obra de María Concepción Amerlinck de Corsi y Manuel Ramos Medina: «El patrono era cesionario de doña Juana y doña María de Yrcio, hijas y herederas de Ruy López de Villalobos — nieto del conquistador y capitán don Pedro de Yncio [o Yrcio]—. ${ }^{79}$

\section{Conclusión}

Las nuevas referencias sobre la biografía de este singular malagueño amplían sin duda un mayor conocimiento del mismo. De esta manera, Ruy López de Villalobos, hijo del segundo matrimonio del leonés Juan de Villalobos con la madrileña doña Juana de Vargas, procedía de un linaje de origen hidalgo perteneciente a la oligarquía malacitana. Su padre ostentó algunas de las magistraturas municipales del cabildo malagueño, a las que sumó la alcaidía de la fortaleza del enclave norteafricano del Peñón de Vélez de la Gomera. Sin embargo, fue su hermanastro Francisco de Villalobos, hijo del primer matrimonio de Juan, así como primogénito del mismo, quien sucedería al cabeza de familia en los cargos de regidor y alcaide, ya que a la muerte de Juan de Villalobos (1512), Ruy era tan solo un niño de corta edad. El linaje de los Villalobos sufrió un duro revés al protagonizar la pérdida del puesto fronterizo del Peñón de Vélez de la Gomera, al caer este en manos musulmanas en 1520, enclave estratégico para controlar los ataques piráticos berberiscos hacia las costas del sur peninsular. Fortaleza que no volvería a recuperarse hasta la segunda mitad del siglo XVI con la exitosa campaña del IV marqués de Villafranca, don García Álvarez de Toledo, en 1564.

Hacia 1530 y rondando la treintena, Ruy López de Villalobos se encontraba en Málaga vendiendo ciertas propiedades, tal vez para invertir el dinero en viajar a América en alguna de las expediciones que se organizaban en ese momento y buscar una oportunidad para aspirar social y

78 AGI, Indiferente, 2064, N. 137.

79 Amerlinck de Corsi y Ramos Medina, 1995, 129. 
económicamente, eligiendo el Nuevo Mundo como lugar de realización de sus sueños como hicieron y hacían muchos de sus contemporáneos. Enrolándose quizás en un primer momento en la expedición de don Pedro de Mendoza hacia el Río de la Plata de 1535, para finalmente desechar esta y embarcarse junto con su hermano menor Bernadirno de Vargas hacia México bajo el amparo de su pariente don Antonio de Mendoza, nombrado virrey de Nueva España ese mismo año.

Como recién llegado al Nuevo Mundo, el malagueño Villalobos tenía varias alternativas para mejorar su posición socio-económica. Una de ellas fue el enlace con hija o descendiente de conquistador; en su caso lo hizo con Juana de Ircio, hija del conquistador Pedro de Ircio, ya que esto le proporcionaría la posibilidad de acceder a encomiendas y optar a puestos en la administración colonial. Otra opción era la participación en nuevas expediciones o hechos bélicos, donde hemos señalado su intervención como jinete durante la denominada guerra del Mixtón y su nombramiento para dirigir una expedición hacia el Pacífico. Por último estaría la protección de alguna autoridad, en su caso por el virrey, ocupando cargos como alguacil mayor de México, teniente de gobernador y capitán general de las Islas de Poniente.

Su parentesco con el virrey, figura de gran poder en Nueva España, sin duda le allanó el camino para conseguir diversos cargos, hasta el momento decisivo de dirigir una expedición de suma importancia para la Corona española como era la colonización de las Filipinas y el hallazgo de la ruta del tornaviaje, proyecto este último que ya habían intentado otros sin demasiada suerte, caso de la «Trinidad» de la armada de Magallanes en 1521 y los dos intentos de Álvaro de Saavedra Cerón con su «Florida» en 1528 y 1529. Sin embargo, la fortuna no estuvo de su parte y en las dos ocasiones en que Villalobos envío el «San Juan» a buscar la vía del tornaviaje a México desde el Pacífico fracasó igualmente. La superación del reto le habría encumbrado a la fama y la consiguiente apertura de las puertas del comercio y la comunicación entre Asia y América, reto que lograría finalmente fray Andrés de Urdaneta en 1565. A ello habría que añadir el incumplimiento de uno de los apartados de la capitulación del viaje, no tocar tierras pertenecientes al Rey de Portugal. En efecto, Villalobos, acumulando fracasos, no tuvo otra opción que recalar en las Molucas portuguesas y, ante el panorama que se le presentaba, decidió pactar con los lusos la repatriación de sus hombres a cambio de los barcos que le quedaban con todos sus aparejos, hecho que le granjeó el descontento de la mayoría de sus oficiales. 
Sin embargo, este gesto de humillación habría que interpretarlo como un acto de consideración, prefiriendo el malagueño salvar a sus hombres. Los supervivientes llegaron a Lisboa en 1548, pero Villalobos no les acompañaría ya que halló la muerte en la isla moluqueña de Ambón dos años antes.

Recibido el 31 de octubre de 2014 Segunda versión: 16 de junio de 2015

Aceptado el 30 de junio de 2015

\section{Referencias bibliográficas}

Alonso, Carlos, Primer viaje misional alrededor del mundo (1542-1549), Valladolid, Estudio Agustiniano, 1989.

Amerlinck de Corsi, María Concepción y Ramos Medina, Manuel, Conventos de monjas: fundaciones en el México virreinal, México, Grupo Condumex, 1995.

Anguita Galán, Eduardo y Moreno Gómez, José, Malagueños en América: del orto al ocaso, Málaga, Ayuntamiento de Málaga, 1992.

Bejarano Robles, Francisco, Los Repartimientos de Málaga, Málaga, Universidad de Málaga y Ayuntamiento de Málaga, 1985, vol. I.

Collazos, Baltasar de, Comentarios de la fundación y conquistas y toma del Peñón, Valencia, 1566, http://www.biblioteca-antologica.org/wp-content/uploads/ 2009/09/COLLAZOS-Comentarios-de-la-Fundaci\%C3\%B3n-y-conquistasy-toma-del-Pe\%C3\%B1on.pdf [Consultado: 29/04/2014].

Cruces Blanco, Esther, «Ensayo sobre la oligarquía malagueña: regidores, jurados y clanes urbanos (1489-1516)», en López de Coca Castañer, José Enrique (ed.), Estudios sobre Málaga y el reino de Granada en el V Centenario de la Conquista, Málaga, Diputación Provincial, 1987, 199-213.

Cuevas Góngora, David, «El linaje de los Anunçibay, vida y poder en la Málaga de los siglos XV-XVII», Baética, 32, Universidad de Málaga, 2010, 279-295.

Díaz del Castillo, Bernal, Historia verdadera de la conquista de la Nueva España, ed. de Miguel León-Portilla, Madrid, Historia 16, 1984, 2 vols.

Dorantes de Carranza, Baltasar, Sumaria relación de las cosas de la Nueva España con noticia individual de los descendientes legítimos de los conquistadores y primeros pobladores españoles, México, Editorial Porrúa, 1987.

Fernández de Recas, Guillermo Sergio, Cacicazgos y nobiliario indígena de la Nueva España: expedientes, México, UNAM, 1961.

Gil, Juan, Mitos y utopías del descubrimiento. II. El Pacífico, Madrid, Alianza, 1989.

González Arévalo, Raúl, La esclavitud en Málaga a fines de la Edad Media, Universidad de Jaén, 2006. 


\section{DAVID CUEVAS GÓNGORA}

Gutiérrez Cruz, Rafael, Los presidios españoles del norte de África en tiempo de los Reyes Católicos, Melilla, Consejería de Cultura, Educación, Juventud y Deporte, 1997.

Landín Carrasco, Amancio, Islario español del Pacífico, Madrid, Cultura Hispánica, 1984.

León el Africano, Juan, Descripción general del África y de las cosas peregrinas que alli hay, traducción, introducción, notas e índices de Serafín Fanjul con la colaboración de Nadia Consolani, Granada, Fundación El Legado Andalusí, 2004.

Mármol Carvajal, Luis del, Descripción general de África, sus guerras y vicisitudes desde la fundación del mahometismo hasta el año 1571, Madrid, Estudios Africanos, 1953, 2 vols.

Martínez Shaw, Carlos, «Estudio Preliminar», en Escalante Alvarado, García de, Viaje a las Islas del Poniente, Santander, Universidad de Cantabria, 1999, 11-37.

Ortuño Sánchez-Pedreño, José María, «La expedición de Ruy López de Villalobos a las Islas del Mar del Sur y de Poniente. Estudio histórico-jurídico», Anales de Derecho, 23, Universidad de Murcia, 2005, 249-292.

Osorio Pérez, María José; Szmolka Clares, José y Moreno Trujillo, María A., Epistolario del conde de Tendilla (1504-1506), Granada, Diputación Provincial, Universidad de Granada, 1996, 2 vols.

Ruiz Povedano, José María, Poder y sociedad en Málaga: La formación de la oligarquía ciudadana a fines del siglo XV, Málaga, Diputación Provincial, 1989.

Santos Arrebola, María Soledad, «Las empresas de Ruy López de Villalobos por el Pacífico», en Actas del V Congreso Internacional de Hispanistas, Málaga, Editorial Algazara, 1999, 23-30.

Thomas, Hugh, Quién es Quién de los conquistadores, Barcelona, Salvat, 2001.

Varela, Consuelo (ed.), El viaje de don Ruy López de Villalobos a las Islas del Poniente, 1542-1548, Milano, Ed. Cisalpino Goliardica, 1983. 